\title{
Risk Factors Concerning Sternal Bone Marrow Aspiration and Patient Safety in Japan
}

\author{
Hiroshi Inoue ${ }^{1}$, Tatsuhiko Nakasato ${ }^{2}$, Kohei Yamauchi ${ }^{1}$, Yutaka Nakamura ${ }^{1}$, Shigemi Oshida ${ }^{3}$ \\ and Shigeru Ehara ${ }^{2}$
}

\begin{abstract}
Objective Several reports have described adverse events resulting from sternal bone marrow aspiration procedures. We hypothesized about inevitable lacerations to the ascending aorta that occur from structural abnormalities in the needle passage.

Methods We evaluated dimensions in the thorax related to the sternal bone marrow aspiration, using a chest $\mathrm{CT}$ scan on a display terminal.

Patients Among the 3,848 patients who visited our institution and underwent a chest CT scan between September 1, 2007 and December 31, 2008, a total of 153 subjects showing no particular chest CT findings were enrolled.

Results Significant variation was observed in the distance from the sternum to the ascending aorta, from a minimum of 4.2 to a maximum of $47.6 \mathrm{~mm}$ (median 23.6) in men and a minimum of 5.2 to a maximum of $38.4 \mathrm{~mm}$ (median 21.3) in women. There were three men (3.6\%) and women (4.3\%) each having a distance within $10 \mathrm{~mm}$.

Conclusion Our findings showed for the first time that an anterior chest approach to sternal bone marrow aspiration involves an inevitable risk of laceration of the ascending aorta, when the needle tip penetrates the sternum. Our analysis of dimension also suggested that the sternal marrow aspiration procedure involved a greater risk among older subjects of short stature.
\end{abstract}

Key words: sternal bone marrow aspiration, dry tap, laceration, ascending aorta, risk factor, chest CT scan

(Inter Med 49: 1089-1095, 2010)

(DOI: 10.2169/internalmedicine.49.3243)

\section{Introduction}

Microscopic examination of marrow is a mainstay of hematological diagnosis (1). Although the posterior iliac crest is currently the preferred site for marrow aspiration and biopsy, the sternum can also be utilized in adults (1), because sternal aspiration was found to be superior to the other procedures in regards to both technical ease and the quality of the marrow obtained (2). A further merit of sternal marrow is thought to be the delay of fat replacement as patients become older, since cellularity decreases fairly steadily with age, accelerating over the age of 70 (3).
Marrow aspirations are more risky, and may fail completely, especially when marrow is densely packed, as in a 'dry tap'. Penetration of the bone may cause damage to underlying structures in all marrow biopsies, but the hazard is greatest in sternal aspirations because the sternum at the second intercostal space is only one $\mathrm{cm}$ thick in adults (1). In the last two decades, the cases of patient deaths caused by sternal bone marrow aspiration procedures have been reported, including some by hematology specialists. We recently realized abnormal access to the ascending aorta via the sternum could be the cause of fatal lacerations, when the needle tip penetrates the sternum. We then hypothesized that there could be an inevitable laceration of the ascending aorta

\footnotetext{
${ }^{1}$ Division of Pulmonary Medicine, Allergy, and Rheumatology, Department of Internal Medicine, Iwate Medical University School of Medicine, Iwate, ${ }^{2}$ Department of Radiology, Iwate Medical University School of Medicine, Iwate and ${ }^{3}$ Department of Legal Medicine, Nihon University School of Medicine, Tokyo

Received for publication December 10, 2009; Accepted for publication February 10, 2010

Correspondence to Dr. Hiroshi Inoue, hiroshi.inoue@r2.dion.ne.jp
} 

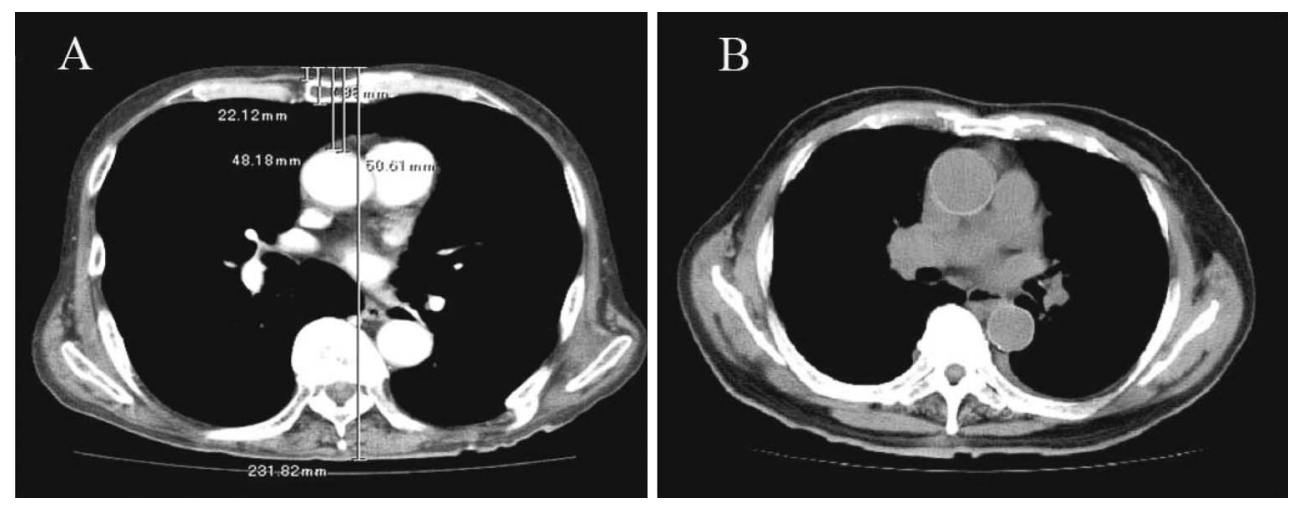

Figure 1. An example of the thoracic dimension measurements of chest $\mathrm{CT}$ images at the sternal bone marrow aspiration level (Panel $A$ ) and a comparison of the chest CT image of a 74-year-old male, $152 \mathrm{~cm}$ tall with possible 'dry tap', showing severe pancytopenia and an excessive access of the ascending aorta with calcification to the sternum who died directly attributable to the procedure, though not included in the present data due to pleural effusion (Panel B).

due to structural abnormalities in the needle passage. However, to our knowledge, no detailed information of the risk factors concerning sternal bone marrow aspiration is available.

This study was aimed to determine the potential risk for sternal bone marrow aspiration procedures by analyzing variations of the thoracic dimensions along with needle passage.

\section{Methods}

\section{Subjects}

Among the 3,848 patients who visited the Iwate Medical University Hospital and had chest CT (computed tomography) scans between September 1, 2007 and December 31, 2008, a total of 153 subjects (20-79 years; 84 men, 69 women) who radiologically had neither chest wall deformation nor abnormal chest CT findings were enrolled in this study.

Images were taken at deep inspiration in the supine position. Chest CT scan images of these subjects were stored in digital form on our computer server. We employed an image presentation system on a display screen (Synapse, Fuji-Film Co., Ltd., Tokyo) and used scaling software (F-Report, FujiFilm Co., Ltd., Tokyo) to measure the thoracic dimensions.

\section{Procedures}

We first retrieved consecutive slices of chest CT scan images at $2 \mathrm{~mm}$ intervals on the display monitor. We then selected chest images coinciding with the sternal center of the second intercostal space from the sequential CT scan, as sternal aspiration is carried out at this level (2) with the needle held perpendicular to the skin.

Starting with the initial slice section level of the sternum at the caudal edge of the 2 nd intercostal space, sequential section levels towards the cephalic edge of the 3rd costal cartilage were identified. The median slice number was re- garded as the center slice section, i.e., the sternal center at the 2nd intercostal space. Where two median slice sections were identified, the cephalic slice section was chosen.

For assessment of the thoracic dimensions, distances from the anterior skin surface to the anterior sternal cortex (skin to pre-sternum), the posterior sternal cortex (skin to poststernum), and the anterior wall of the ascending aorta (skin to aorta) were measured (Fig. 1, Panel A). When the ascending aorta deviated from the anterior-posterior center line of the thorax, the shortest distance from the center of the skin surface to the organ was obtained. Sternal bone thickness was obtained by subtracting the distance of the skin to presternum from the distance of the skin to post-sternum. The distance from the post-sternum to aorta was obtained by subtracting the distance of the skin to the post-sternum, from the distance of the skin to the aorta.

As intravenous contrast material was not used in most subjects, measuring the thickness of the wall of the ascending aorta was not possible. The distance from the sternum to the heart or pericardium was not measured, since this was not observed in the CT slice sections selected for the measurement of the thoracic dimensions. It has been pointed out that aspiration from the sternum at the 3rd intercostal space increases the risk of laceration to the heart, due to the short distance between the skin and heart (4).

We measured actual distances in millimeters, rounded to two decimal places. Time resolution of the chest CT scan was more than one second, so that the dimension of the large vessels would reflect the outer diameter of pulsation.

As the study was conducted retrospectively, neither consideration of the ethical committee of our medical school nor written consent from the subjects was obtained. Personal data protection was adopted, and names, addresses, telephone numbers, and interview records of all the subjects were not accessed and remained confidential.

\section{Data analyses}

Data were expressed as the mean \pm SD. All statistical 
A

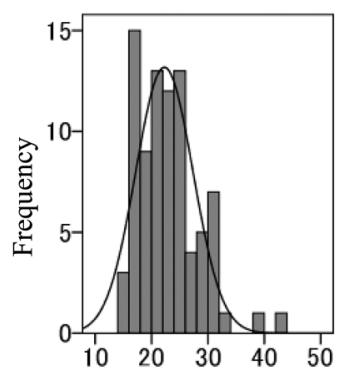

$\mathrm{E}$

Skin to Post-sternum (mm)

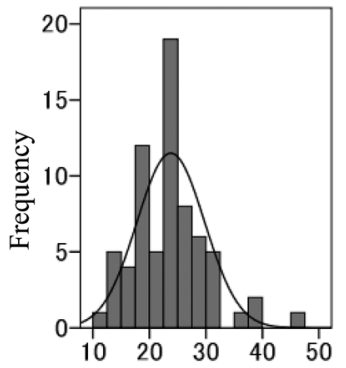

Skin to Post-sternum (mm)
B

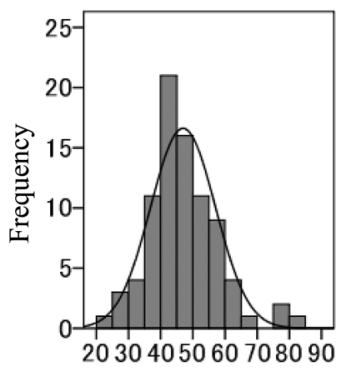

Skin to Aorta (mm)

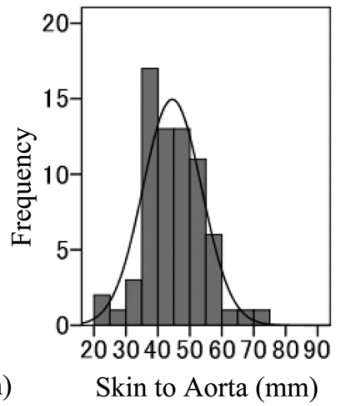

$\mathrm{C}$

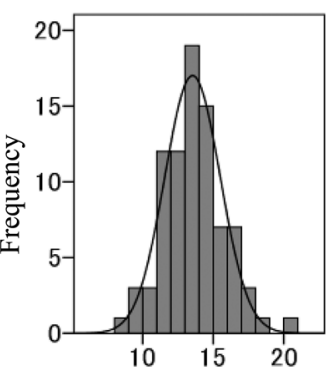

Thickness of Sternum (mm)

G

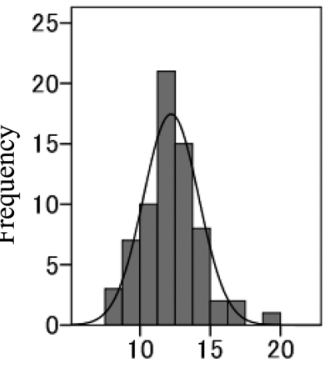

Thickness of Sternum (mm)
D

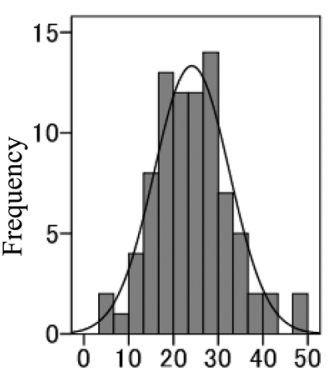

Sternum to Aorta (mm)

$\mathrm{H}$

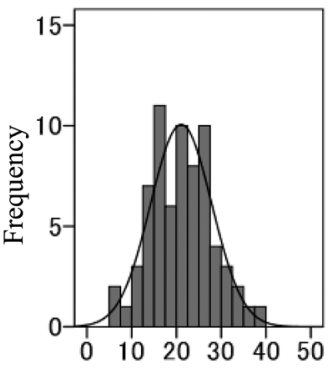

Sternum to Aorta (mm)

Figure 2. Variation in the thoracic dimensions. Distance from the anterior skin surface of the sternum to the posterior sternal cortex (skin to post-sternum) (Panels A and E), from the forward skin surface of the sternum to the anterior wall of the ascending aorta (skin to aorta) (Panels B and F), from the forward surface to the posterior surface of the sternum (thickness of sternum) (Panels C and G), and from the posterior surface of sternum to the anterior wall of the ascending aorta (post-sternum to aorta) (Panels D and H). *Upper panels represent the mens group, and lower panels the womens group.

Table 1. Anthropometric Data and Thoracic Dimensions Related to Sternal Bone Marrow Aspiration.*

\begin{tabular}{|lcccc|}
\hline & $\begin{array}{c}\text { Total } \\
(\mathbf{n = 1 5 3})\end{array}$ & $\begin{array}{c}\text { Men } \\
(\mathbf{n = 8 4})\end{array}$ & $\begin{array}{c}\text { Women } \\
(\mathbf{n = 6 9 )}\end{array}$ & p Value $\dagger$ \\
Age, mean (SD), y & $54.2 \pm 15.1$ & $52.6 \pm 15.6$ & $56.1 \pm 14.3$ & 0.161 \\
Height, mean (SD), cm & $161.8 \pm 9.7$ & $168.1 \pm 7.6$ & $154.4 \pm 6.0$ & $<0.001$ \\
Weight, mean (SD), kg & $61.5 \pm 12.2$ & $68.7 \pm 10.9$ & $53.1 \pm 7.2$ & $<0.001$ \\
BMI, mean (SD) & $23.3 \pm 3.1$ & $24.3 \pm 3.1$ & $22.3 \pm 2.6$ & $<0.001$ \\
Skin to anterior sternal cortex, mean (SD), mm & $10.2 \pm 4.9$ & $9.4 \pm 4.4$ & $11.3 \pm 5.3$ & 0.014 \\
Skin to posterior sternal cortex, mean (SD), mm & $23.2 \pm 5.8$ & $23.0 \pm 5.3$ & $23.6 \pm 6.3$ & 0.531 \\
Thickness of sternum, mean (SD), mm & $13.4 \pm 2.2$ & $13.6 \pm 2.1$ & $12.2 \pm 2.1$ & $<0.001$ \\
Skin to ascending aorta, mean (SD), mm & $46.0 \pm 10.2$ & $47.1 \pm 10.8$ & $44.6 \pm 9.3$ & 0.138 \\
Posterior sternal cortex to ascending aorta, mean (SD), mm & $22.7 \pm 7.9$ & $24.1 \pm 8.5$ & $21.1 \pm 6.8$ & 0.017 \\
A-P caliber of thorax, mean (SD), mm & $198.2 \pm 19.7$ & $208.2 \pm 16.4$ & $186.0 \pm 16.3$ & $<0.001$ \\
\hline
\end{tabular}

$\dagger \mathrm{p}<0.05$ indicates a significant difference between the men's and women's group.

analysis was performed using software (IBM SPSS Statistics 18, SPSS Japan Inc., and IBM Co.). Unpaired Student t-test was employed to compare the data of the independent two groups and considered significant, when $\mathrm{p}$ was $<0.05$.

\section{Results}

\section{Anthropometric data and thoracic dimensions}

Mean age of the enrolled subjects was 52.6 \pm 15.6 (SD) years for men and $56.1 \pm 14.3$ years for women, with no significant difference $(\mathrm{p}=0.161)$; mean height was $168.1 \pm 7.6$ $\mathrm{cm}$ for men and $154.4 \pm 6.0 \mathrm{~cm}$ for women, showing a significant difference $(\mathrm{p}<0.001)$; mean BMI (body mass index) was $24.3 \pm 3.1$ for men and $22.3 \pm 2.6$ for women, with a significant difference $(\mathrm{p}<0.001)$ (Table 1$)$. It is noteworthy that the thoracic dimensions related to sternal bone marrow aspiration largely varied among individual subjects by a factor of two to ten (Fig. 2, Panels D and H). Significant mean differences of the factors were also observed between men 

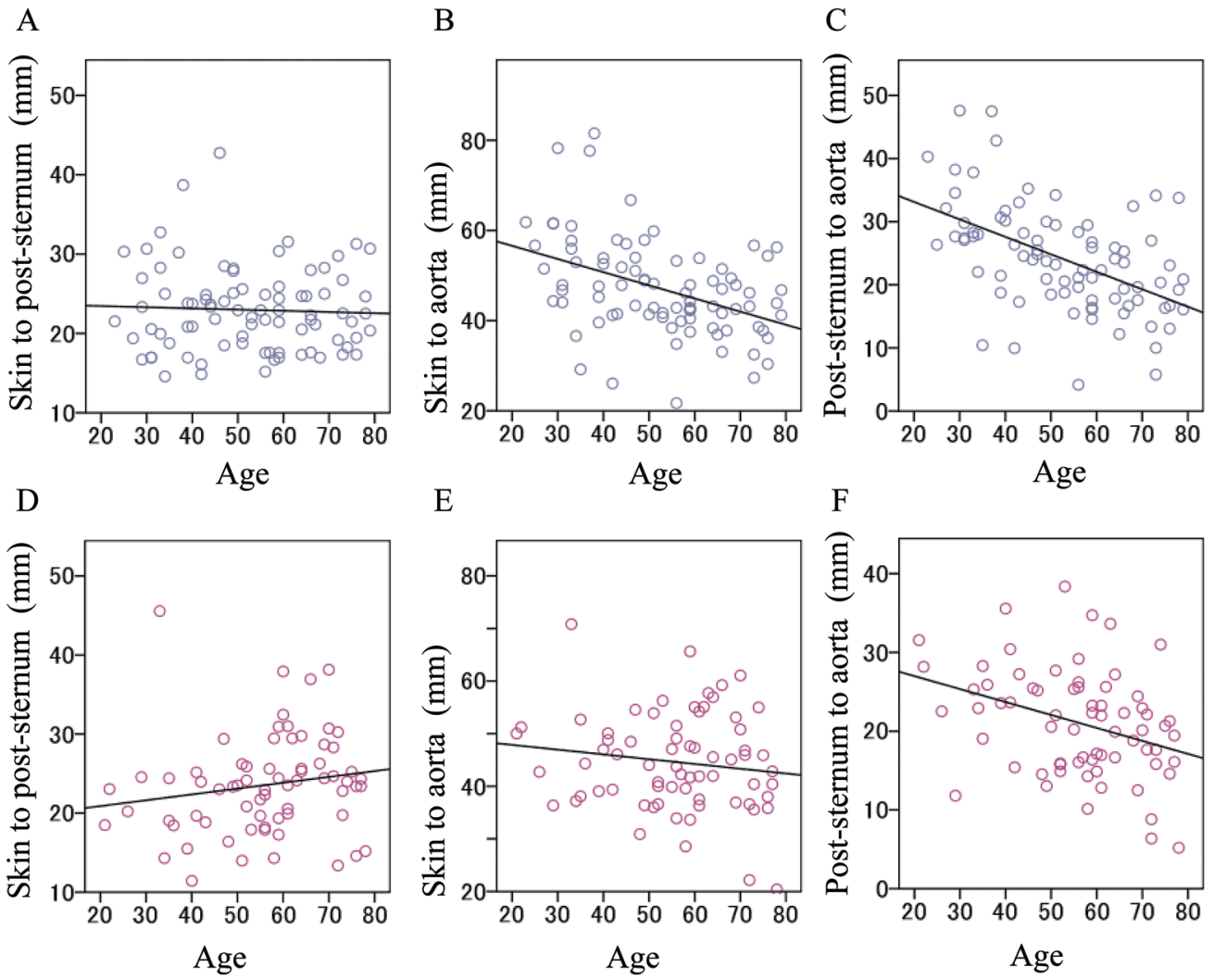

Figure 3. Relationship between age and the distances from the skin to post-sternum from the skin to the aorta, and from the post-sternum to the aorta in men and women. *Upper panels represent the mens group, and lower panels the womens group.
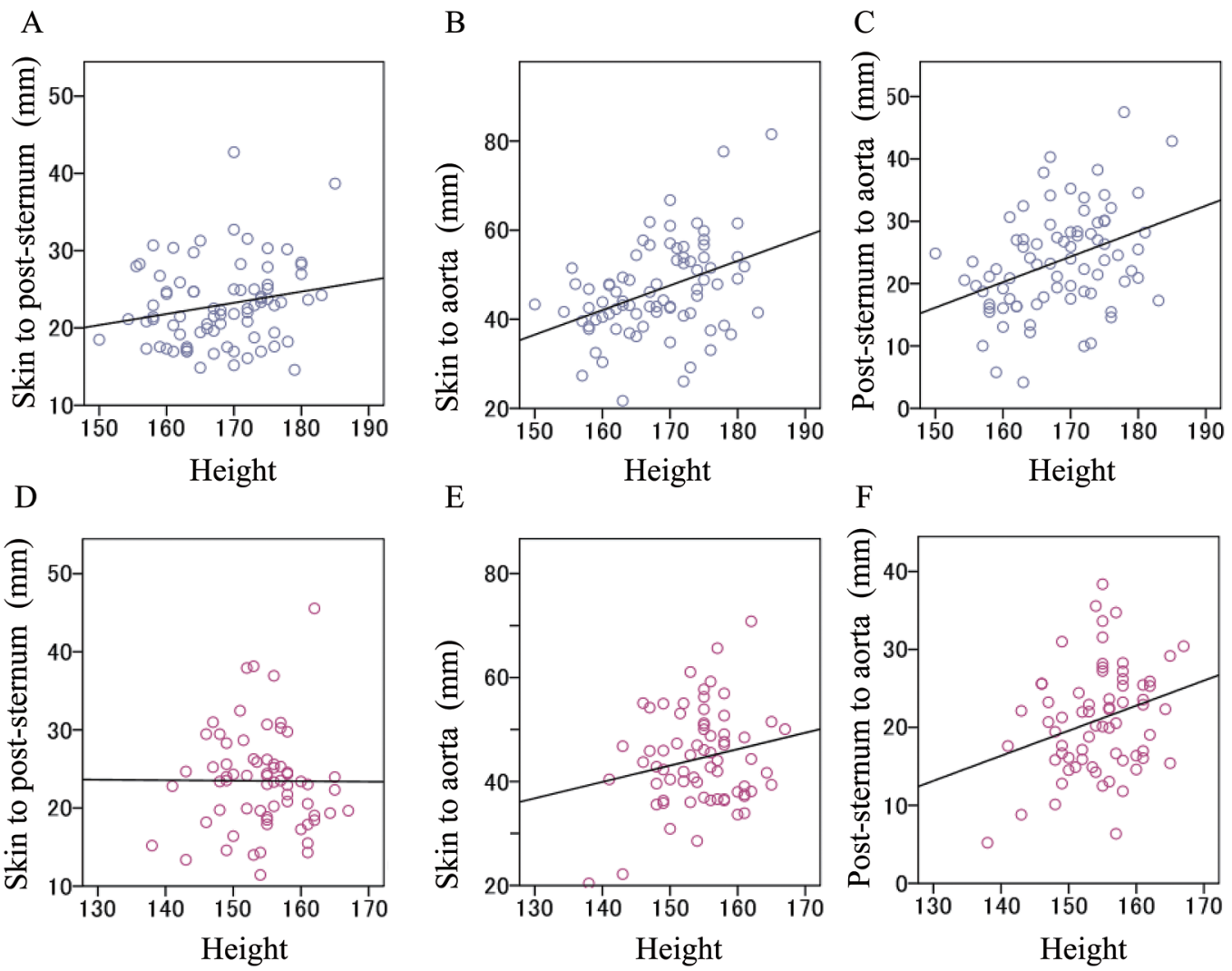

Figure 4. Relationship between height and the distance from the skin to the post-sternum, from the skin to the aorta, and from the post-sternum to the aorta in men and women. *Upper panels represent the mens group, and lower panels the womens group. 
A

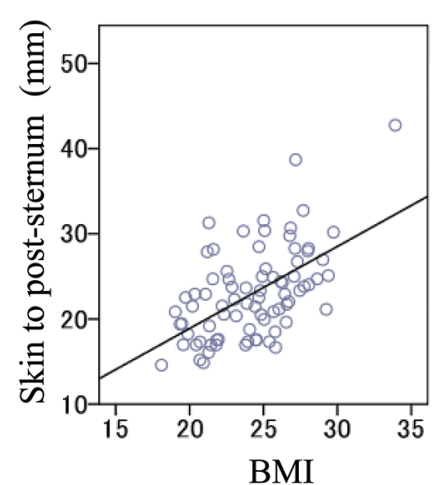

D

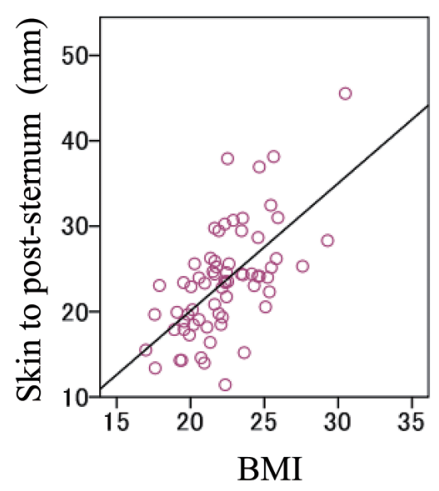

B

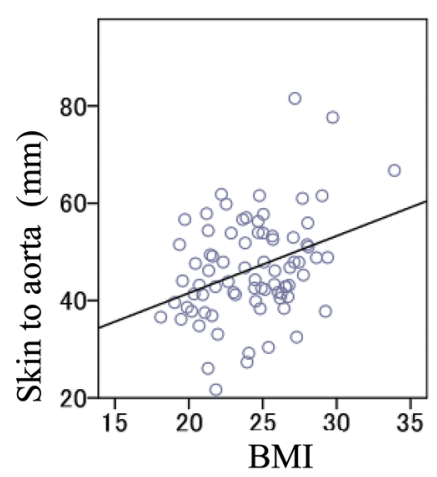

E

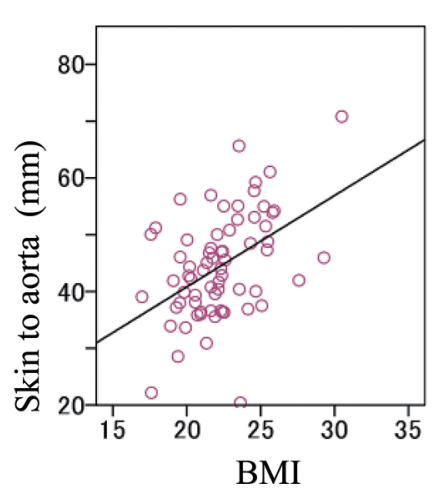

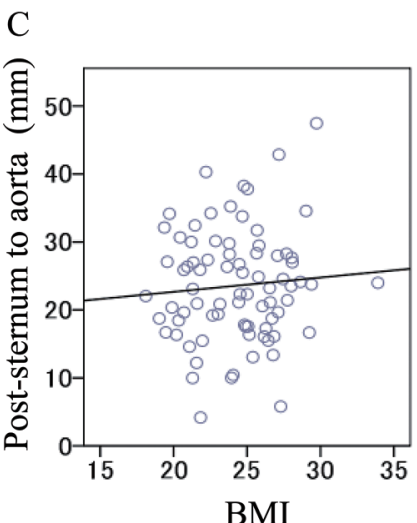

$\mathrm{F}$

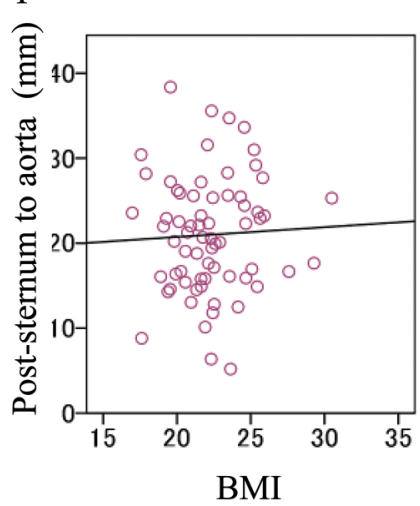

Figure 5. Relationship between BMI and distances from the skin to the post-sternum, from the skin to aorta, and from the post-sternum to the aorta in men and women. *Upper panels represent the mens group, and lower panels the womens group.

and women, except for the distance from the skin to the post-sternum and from the skin to the aorta (Table 1). The actual mean thickness of the sternum was $13.0 \pm 0.2 \mathrm{~mm}$ in adults at the 2nd mid-intercostal level.

\section{Correlation between anthropometric data and tho- racic dimension}

Interestingly, a significant inverse correlation was observed between age and the distance from the skin to the aorta in men $(r=-0.421, \mathrm{p}<0.001)$ but not in women ( $r=-$ 0.139, $\mathrm{p}=0.253$ ) (Fig. 3, Panels B and E), and a significant inverse correlation was also observed between age and the distance from the post-sternum to the aorta in men and women ( $\mathrm{r}=-0.508, \mathrm{p}<0.001$; $\mathrm{r}=-0.344, \mathrm{p}=0.004$ ) (Fig. 3, Panels $\mathrm{C}$ and $\mathrm{F}$ ), indicating that age influenced the intrathoracic dimensions. A significant inverse relationship between age and height was observed in men and women $(\mathrm{r}=-0.470, \mathrm{p}<$ $0.001 ; \mathrm{r}=-0.527, \mathrm{p}<0.001)$, thus age may be a cofactor of height in the present data. Additionally, a significant correlation was observed between height and the distance from the skin to the aorta in men $(\mathrm{r}=0.402, \mathrm{p}<0.001)$ but not in women ( $\mathrm{r}=0.202, \mathrm{p}=0.099$ ) (Fig. 4, Panels B and E), and a significant correlation was also observed between the height and the distance from the post-sternum to the aorta in men and women $(\mathrm{r}=0.378, \mathrm{p}=0.001 ; \mathrm{r}=0.279, \mathrm{p}=0.021)$ (Fig. 4, Panels $\mathrm{C}$ and $\mathrm{F}$ ), indicating that the height influenced the intrathoracic dimensions as expected. A significant correlation was observed between the BMI and the distance from the skin to the post-sternum in men $(\mathrm{r}=0.558, \mathrm{p}<0.001)$ and women $(r=0.622, p<0.001)$ (Fig. 5, Panels A and D), and a significant correlation was also observed between the BMI and the distance from the skin to the aorta in men $(r=0.346$, $\mathrm{p}=0.002)$ and women $(\mathrm{r}=0.456, \mathrm{p}<0.001)$ (Fig. 5, Panels B and $\mathrm{E}$ ), indicating BMI influenced the outer thoracic dimensions in the present study.

\section{Discussion}

Marrow aspiration needles are available in several types, lengths, and calibers (5). Aspiration needles are 22-, 30-, or 40-mm long in different gauges with a changeable safety stopper. The stopper, however, does not necessarily prevent deeper tissue penetration.

The present data indicate that a $22-\mathrm{mm}$ needle can penetrate the mediastinum in $47.6 \%$ of men and $39.1 \%$ of women, reaching the anterior wall of the ascending aorta in $1.2 \%$ of men and $1.4 \%$ of women, when inserted at full length. The data also indicate that a $30-\mathrm{mm}$ needle can penetrate the mediastinum in $94.0 \%$ of men and $90.0 \%$ of women, reaching the anterior wall of the ascending aorta in $6.1 \%$ of men or $2.9 \%$ of women, when inserted at full length. In addition, compression force on the sternum during advancement of the needle may cause thoracic cage deformation, resulting in the needle reaching the anterior wall of the ascending aorta. The distance from the sternum to the anterior wall of the ascending aorta may vary depending 
upon the lung volume. If the inspiration volume during the marrow aspiration maneuver is less than that shown during the chest CT scans in this study, the tip of the needle may advance to the anterior wall of the ascending aorta. As subjects with hypertension, arteriosclerosis, or thoracic disorders may demonstrate a tortuous aorta and certain intrathoracic lesions may change the dimensions, further study would be required to clarify the risk factors in more detail. In addition, aspirin and warfarin therapy, disseminated intravascular coagulation, obesity, and platelet dysfunction have also been suggested to be potential risk factors for massive hemorrhage (6).

The present study found that the subjects of older age and short stature revealed shorter distances from the poststernum to the aorta in men and women, suggesting a higher risk of aortic laceration when the needle tip penetrates the sternum. The data revealed that five of six subjects for whom the procedure resulted in fatality in recent decade in our country were more than seventy years old, though the degree of correlation between the anthropometric factors and the dimensions was not so high, these factors may not necessarily be able to predict the risk from sternal bone marrow aspiration.

Several reports have cited medical literature indicating morbidity, even mortality, as a result of bone marrow aspiration procedures. Although deaths are extremely rare, close to 23 cases were reported by 2001 amongst European nations $(4,6)$. The deaths were mainly a consequence of a laceration of a great vessel or heart with pericardial tamponade. The British Society of Hematology (BSH) carried out a postal survey of adverse events associated with bone marrow biopsy among its members between 1995 and 2001 mainly in England. The survey revealed a total of 26 adverse events, including serious adverse effects in 14 subjects, with massive hemorrhage and a single death directly attributed to the procedure, among a total estimated 54,890 procedures (aspiration biopsy with or without trephine biopsy), involving specialist hematologists and consultants (6). Since then, the posterior iliac crest has become the preferred site for marrow aspiration and biopsy amongst European nations.

In Japan, serious adverse outcomes have been reported during sternal marrow aspiration. Death occurred in at least 4 cases between 2002 and 2004 (7), with an additional two between 2006 and 2007. Of these 6 patients, 5 were over 70 years old, suggesting a risk in old age, while the other patient was 46 years old. The reported possible causes of the patients' death included hemorrhagic shock and cardiac tamponade due to laceration of the ascending aorta induced by sternal bone marrow aspiration. One case reported in 2003 involved a highly trained specialist with an experience record of over 300 bone marrow aspirations. The case reported in 2006 also involved a specialist hematologist and preceptor with experience of more than 100 bone marrow aspirations with the possible cause of laceration by the needle tip during local anesthesia (8). It is therefore fair to postulate that sternal bone marrow aspiration involves the inevi- table risk of laceration of the ascending aorta, with the number of adverse events increasing proportionally to that of bone marrow aspirations conducted.

The principal problem in performing bone marrow procedures occurs when operators rely upon sensation for the sudden penetration of the frontal cortex. The most common cause for failure to obtain marrow may be faulty positioning of the needle, while a second attempt is usually successful (1). Although this can happen when the bone marrow histology is normal, in 'dry taps', further needle penetration through the sternum into the mediastinum could occur during insertion, when the operator may feel an lessenning of resistance. Dry tap usually indicates the presence of significant disease, most often metastatic cancer, chronic myeloid leukemia, idiopathic myelofibrosis, hairy cell leukemia with associated fibrosis $(4,5,9)$, or multiple myeloma (10). As leukemic or fibrotic marrow may be very densely packed, penetration through the sternum may occur.

If the overall incidence of bone marrow dry taps was between $3.9-6.8 \%$ as reported (9-12), a possible $10 \mathrm{~mm}$ proximity of the ascending aorta to the sternum, as in this study, of $3.6-4.3 \%$, and a $10 \%$ laceration rate of the ascending aorta by the biopsy needle (including fatal injury of an aorta made fragile by arteriosclerosis in the aged) are overlapped, the total risk would be $0.01-0.03 \%$, which may be coincident with the speculated total risk of death of less than $0.05 \%$ provided in previous reports $(1,6)$.

This sort of patient death may be regarded to be a rare event, but it is definitely not acceptable to the patients or their families. At present, the procedure for bone marrow aspiration has not been restricted to only specialist hematologists and has been undertaken by general physicians, because it was considered a fundamental technique to be learned by postgraduate trainees under the supervision of senior physicians. This then becomes the potential responsibility of the medical academic society to ensure the medical safety of the procedure. In June, 2009, the Japanese Society of Hematology for the first time warned in a document on their home page, with a great delay of the public coment, compared with the European Medical Society that sternal bone marrow aspiration should be carried out with great care because the procedure is likely to cause serious complications such as massive hemorrhage or pericardial tamponade (13). The present study may provide scientific evidence for recent movement against obtaining sternal bone marrow specimens. During the past decade, awareness and understanding of medical errors have expanded rapidly, with an energetic patient safety movement promoting safer health care through "systems" solutions (14). Hence, the prevention of harm plays a critical role in medical safety. The prevention of adverse events occurring with the special procedures and medicaments may rely upon responsibilities of the wrresponding medical societies.

In conclusion, the present data suggests that sternal bone marrow aspirations carry an inevitable risk of laceration to the ascending aorta involving a greater risk among older 
subjects of short stature.

\section{Acknowledgement}

This study was partly supported by research funding from the Ministry of Education, Culture, Sports, Science and Technology, Japan.

\section{Authors' contribution}

HI had full access to all of the data in the study and takes re- sponsibility for the integrity of the data and the accuracy of the data analysis. TN and KY equally contributed to this work. HI, $\mathrm{TN}$, and SE contributed to the study concept and design; HI and TN contributed to the acquisition of the data. HI, KY, YN, and SO contributed to the analysis and interpretation of the data. HI, YN, and SE contributed to drafting of the manuscript. SO and SE contributed to the critical revision of the manuscript for important intellectual content.

\section{References}

1. Ryan DH, Felgar RE. Examination of the marrow. In: Williams Hematology. 7th ed. Lichtman MA, Beutler E, Kipps TJ, Seligsohn URI, Kaushansky K, Prchal JT, Eds. McGraw-Hill, New York, 2006: 21-31.

2. Bennike T, Gormsen H, Moller B. Comparative studies of bone marrow punctures of the sternum, the iliac crest, and the spinous process. Acta Med Scand 155: 377-396, 1956.

3. Hartsock RJ, Smith EB, Petty CS. Normal variations with ageing of the amount of hematopoietic tissue in bone marrow from the anterior iliac crest; a study made from 177 cases of sudden death examined by necropsy. Am J Clin Pathol 43: 326-331, 1965.

4. Bain BJ. The normal bone marrow. In: Bone Marrow Pathology. 3rd ed. Bain BJ, Clark DM, Lampert LA, Willkins BS, Eds. Blackwell Science, Oxford, 2001: 1-50.

5. Riley RS, Hogan TF, Pavot DR, et al. A pathologist's perspective on bone marrow aspiration and biopsy; I. Performing a bone marrow examination. J Clin Lab Anal 18: 70-90, 2004.

6. Bain BJ. Bone marrow biopsy morbidity and mortality. Br J Hematol 121: 949-951, 2003.

7. Wakimoto N. Bone marrow aspiration-strategy to avoid fatal com- plications. Jpn J Intern Med 17: 230-234, 2005.

8. Naoe T, Ozawa K, Sugita M, Takeshita A. A document of a medical accident rapporteur of the Shimada Municipal Hospital. October 3rd, 2006. Available at: http://www.municipal-hospital.shimada.sizuoka. jp. Accessed January 20, 2010.

9. Weisberger AS. The significance of 'dry tap' bone marrow aspirations. Am J Med 229: 63-68, 1955.

10. Humphries JE. Dry tap bone marrow aspiration: clinical significance. Am J Hematol 35: 247-250, 1990.

11. Hyun BH, Gulati GL, Ashton JK. Bone marrow examination: technique and interpretation. Hematol Oncol Clin North Am 2: 513-523, 1988.

12. Navone R, Colombano MT. Histopathological trephine biopsy findings in cases of 'dry tap' bone marrow aspirations. Appl Pathol 2: 264-271, 1984.

13. Kurokawa M, Ikeda Y. A caution of the site for the bone marrow aspiration in adults. In: New Information on June 4th, 2009. The Japanese Society of Hematology, http://www.jshem.or.jp/

14. Newman-Toker DE, Pronovost PJ. Diagnostic errors-the next frontier for patient safety. JAMA 301: 1060-1062, 2009.

(C) 2010 The Japanese Society of Internal Medicine http://www.naika.or.jp/imindex.html 